Scottish Geographical Journal

\title{
A Virtual Geography of the Scottish Islands
}

\section{Ruth Wilson, Claire Wallace \& John H. Farrington}

To cite this article: Ruth Wilson, Claire Wallace \& John H. Farrington (2015) A Virtual Geography of the Scottish Islands, Scottish Geographical Journal, 131:3-4, 228-244, DOI: 10.1080/14702541.2015.1034761

To link to this article: http://dx.doi.org/10.1080/14702541.2015.1034761 \section{(c) 2015 The Author(s). Published by Taylor \&
Francis.}

曲 Published online: 20 Apr 2015.

\section{Submit your article to this journal}

\section{Џ Article views: 48}

Q View related articles $₫$

View Crossmark data $\nearrow$ 


\title{
A Virtual Geography of the Scottish Islands
}

\author{
RUTH WILSON $^{\mathrm{a} *}$, CLAIRE WALLACE $^{\mathrm{b}} \&$ JOHN H. FARRINGTON ${ }^{\mathrm{c}}$ \\ ${ }^{a}$ dot.rural RCUK Digital Economy Hub, University of Aberdeen, Aberdeen, UK; ${ }^{b}$ Department of Sociology, \\ University of Aberdeen, Aberdeen, UK; ${ }^{c}$ Department of Geography, University of Aberdeen, Aberdeen, UK
}

(Received 20 March 2015; accepted 23 March 2015)

\begin{abstract}
Communications technologies, and in particular the Internet, support the formation of vast and distributed social networks and are fuelling changes in sociability. For residents of remote rural regions, they offer the promise of overcoming geographical barriers and enabling isolated and dispersed individuals to link to each other and to the rest of the world. However, speculation concerning such social transformations in rural areas has been largely unsupported by empirical evidence. This paper presents a case study of 350 bloggers from across the Scottish islands. By examining the connections they form (using social network analysis) and their discursive interactions (through a thematic analysis), it aims to show how the islanders make use of their digital connectivity. The social network analysis reveals a high degree of interaction between bloggers and commenters: within each island; between the islands; and with the outside world, as they reach beyond the limitations of their physical place. However, an analysis of the bloggers' discourse shows that it is new associations with other islanders, based on a common islander identity, that they seek to explore through their digital connectivity. The physical and metaphorical boundaries of island social life are not so much crossed and broken as flexed and stretched by the possibilities of the digital world.
\end{abstract}

KEY WORDS: rural geography, social geography, digital technology, social network analysis, blogs

\section{Introduction}

The relationship between sociability and geographical place has been a key concern for sociologists since the foundation of the discipline, with particular forms of social relation associated with rural and urban regions (Sorokin \& Zimmerman 1929; Wirth 1938; Weber [1904] 1946; Durkheim [1893] 1997). This focus on locational dimensions has since been questioned (Pahl 1968), and a recent wave of contemporary theories suggests that people are increasingly connecting through digital technologies across space and that the role of place in the formation and maintenance of social ties is receding in importance (Castells 2000; van Dijk 2012; Rainie \& Wellman 2012).

In his theory of the network society, Castells (2000) argues that the proliferation and diffusion of information and communication technologies over the last four decades has facilitated the formation of vast and complex social structures based on network configurations:

Correspondence Address: Ruth Wilson, dot.rural RCUK Digital Economy Hub, University of Aberdeen, Aberdeen, UK. Email: ruthwilson@abdn.ac.uk

(C) 2015 The Author(s). Published by Taylor \& Francis.

This is an Open Access article distributed under the terms of the Creative Commons Attribution License (http:// creativecommons.org/Licenses/by/4.0/), which permits unrestricted use, distribution, and reproduction in any medium, provided the original work is properly cited. 
'We know that technology does not determine society: it is society' (Castells 2005, p. 3, his emphasis). A key feature of the new social structures is that they are less defined by physical locality (a 'space of places') than by a geographically flattened 'space of flows':

the space of flows [...] links up distant locales around shared functions and meanings on the basis of electronic circuits and fast transportation corridors, while isolating and subduing the logic of experience embodied in the space of places.

(Castells 2001a, pp. 155-178)

These global social formations create conditions for new forms of sociability in which traditional, place-based communities are replaced by connections that stretch across space: 'new, selective patterns of social relations substitute for territorially bound forms of human interaction' (Castells 2001b, p. 116). Connections in the network society are heterogeneous, individualised and fluid, in contrast to the enduring, deeply rooted relationships of geographically based communities (Rainie \& Wellman 2012). This distinction is expressed in Wittel's description of the 'network sociality' facilitated by new forms of connectivity:

In network sociality social relations are not 'narrational' but informational; they are not based on mutual experience or common history, but primarily on an exchange of data and on 'catching up' [...] Network sociality consists of fleeting and transient, yet iterative social relations; of ephemeral but intense encounters.

(2001, p. 51)

Policy-makers are hopeful about the potential for such technologies, and the social transformations they bring, for remote rural regions, postulating that long-standing disadvantages associated with geographic remoteness can be overcome: 'Digital communication can help to improve communications within scattered populations and between them and the outside world' (The Royal Society for Edinburgh 2010, p. 30). However, the limited evidence available from other studies has highlighted the heterogeneity of rural residents in terms of their social motivations for using the Internet (Lægran 2002; Gannon 2007) and that rural Internet users tend to replicate pre-existing social behaviours online (Gilbert et al. 2010; Stern \& Adams 2010). Assumptions of the 'death of distance' for rural residents in Britain, though, are untested (Cairncross 1997). Spencer and Pahl (2006) underline the importance of acquiring knowledge about the potential and constraints of digital technologies in this respect:

While some people are very embedded in their local neighbourhood, with most of their friends and family living within one or two miles, others sustain significant relationships across hundreds and even thousands of miles. Of course, people's ability to retain dispersed contacts has been aided by the expansion, and the reduction in cost, of communication technologies, but we need to understand which kinds of relationships tend to be local and which can be maintained without immediate access or face-to-face contact.

(Spencer \& Pahl 2006, p. 53)

The research presented here addresses this issue through a case study of Scottish island bloggers, asking, what is the role of geographical location in digital sociability for rural 
residents? In the following sections, the paper introduces the background and context of the Island Blogging project that formed the material for this research. It examines how the islanders used the blogs to form connections, through a social network analysis, and how they understood the spatial dimensions of these connections, through a thematic analysis of their reflections and discussions.

\section{Background and Context}

The Island Blogging project was part of a 2001 Digital Communities initiative by the then Scottish Executive to increase digital connectivity and literacy in one urban and one rural region of Scotland. Argyll and Bute Council prepared a bid to join the scheme, which stated that:

[While the islands] are rich in bio-diversity, culture, history, archaeology, renewable energy opportunities, and landscape, they suffer from many issues of deprivation and disadvantage both caused and accentuated by their geographic isolation [...] there are very real issues of social exclusion that are related to remoteness and which tend to be exhibited most dramatically on islands.

(Argyll \& Bute Council 2002, pp. 2-3, quoted in Malina \& Macintosh 2004, p. 265)

The Council held high hopes for the project, summarised in Councillor Ian Gillies' statement on the announcement that the bid had been successful:

Our island communities will be able to communicate with each other and the rest of the world by email, voice chat or web camera, as well as having the means to access public services, learning materials, information, or simply internet shopping on-line. The ability to maintain contact with family and friends, living or working away from home, will be a huge boost to family stability and help overcome the challenges of distance and isolation.

(Scottish Executive 2002)

As a result of the successful bid, 13 of the 26 inhabited islands in the Argyll and Bute archipelago, totalling 2145 households (4290 people), benefited from free (dial-up, or 'narrowband') Internet access for one year, a PC, a printer, a webcam and software (Malina \& Macintosh 2004). In addition, Argyll and Bute Council teamed up with the BBC to encourage the islanders to make use of their new technology and to share experiences of life on Scottish islands through the Island Blogging project. This enabled island residents to contribute stories and images to appear on blogs on a dedicated area of the BBC Scotland (2010) website, 'offering a unique insight into daily life on Scottish islands'.

While the provision of hardware and free Internet access remained limited to the original bid-winning group of 13 islands, Island Blogging itself subsequently expanded to include the other Scottish islands, with staff from BBC Scotland touring the area, presenting the concept in village halls and community centres and explaining the basics of blogging; technical support was also provided electronically by BBC moderators to new bloggers as required. The result was a large corpus of blogs, organised according to three island groups: Argyll and Clyde, the Western Isles and the Northern Isles (Figure 1). While there are several ways of classifying the islands into groups, for example, by council 
area or by Haswell-Smith's (2004) classification, this paper follows the classification used on the Island Blogging site itself; however, note that Skye, which is commonly grouped in the Inner Hebrides, is here grouped together with the Western Isles.

As well as setting up and hosting the blogs, the BBC oversaw the day-to-day running of the project. This involved monitoring, in so far as was possible, eligibility to write a blog on the site (bloggers had to be over 14 years old and resident on a Scottish island), checking that posts and comments adhered to a set of 'House Rules' that explained the behaviour expected of all contributors to the site (e.g. no flaming, harassment or abuse) and filtering out spam. In addition, BBC moderators maintained their own 'IBHQ' (Island Blogging Headquarters) blog, used to welcome new bloggers to the site, announce technical upgrades and post news of relevance to the islands; under the IBHQ moniker the moderators also made and received comments, joined in the bloggers' discussions and remained a visible presence and an active part of the site throughout.

The blogging project ran until, in November 2008, the BBC announced that the site would be closing, stating that it had fulfilled its purpose of increasing digital literacy in the islands and that the blogging engine was becoming increasingly problematic and outmoded. When the project eventually ended in 2010, the blogs were archived and remain publicly available on the BBC website (www.bbc.co.uk/scotland/islandblogging).

\section{Methods}

First, a social network analysis of the entire BBC Island Blogging archive was performed. This involved mapping the connections that were formed via the blogs' network of 54,473

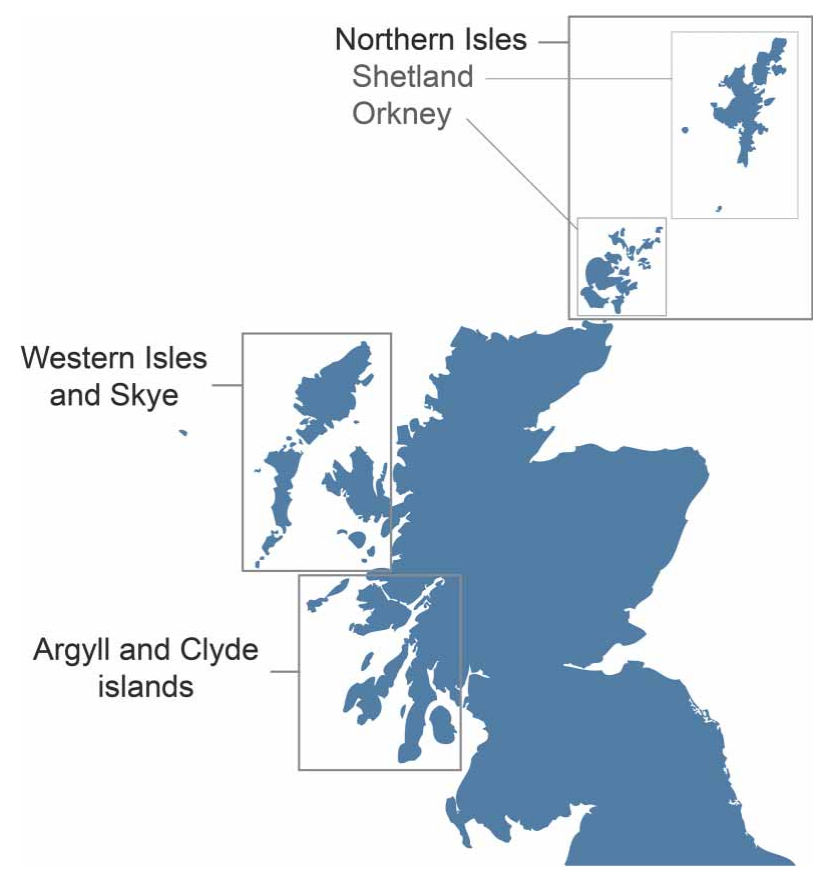

Figure 1 Scottish island groupings on the Island Blogging site. 
comments on 5672 posts written by 345 bloggers between 2003 and 2010. Every instance of a comment on each of the island blogs, across the duration of the project, was collated in an Excel spreadsheet, noting the following: name and location of commenter (provided by them, through free text fields); name of blog post on which the comment was made; location of blog on which the comment was made (by island and island group); and date of the post on which the comment was made. These data were then imported to NodeXL, a social network visualisation tool, to analyse the emerging structures (Social Media Research Foundation 2014).

Second, an analysis of the content of the island blogs (text and comments) was performed, in a five-stage process of identifying and classifying emerging themes and patterns.

Stage 1 involved immersion of the researcher in the online environment, reading all of the blogs and their comments systematically in their native format (retaining their layouts, designs and images as readers and contributors would have experienced them at the time) for an overall impression of what was said by whom, and how. This stage gave a sense of broad themes and of the personae of the bloggers and commenters, and proved critical in understanding the tone of the blogs.

In stage 2, a sample of 752 posts (individual blog entries and their comments) was selected and imported to NVivo. This involved a systematic process of reading and selecting to arrive at a sample of posts that was rich, manageable and pertinent to the research question. Posts were selected in which the relationship between geographical location and digital sociability was either explicitly reflected on or discussed, or implicitly demonstrated through the bloggers' conversations. The selection process adopted a broad view of sociability that was receptive to islanders' own definitions and understandings, in order not to impose preconceptions about what form it might take for the blogging islanders. The sample therefore included but was not limited to articulations of isolation, friendship, community, belonging and exclusion that spanned online and offline settings, as well as indirect expressions of the Internet's social role.

Stage 3 involved initial coding of blog extracts following further close reading. This was guided by the research question while allowing codes to emerge from the data (Charmaz 2006).

In stage 4 (focused coding), the codes were sorted, synthesised and organised to develop the main conceptual categories emerging from the blogs. This involved rereading the blogs in conjunction with their associated initial codes to identify widely used codes, recurring ideas and groupings that made the most analytic sense in relation to the bloggers' reflections and discussions. For example, the codes 'Island Blogging as community' and 'Island Blogging as friend or family' were connected at this stage, since they both relate to how the bloggers conceptualise their online environment. The result of this stage was a smaller but arguably more insightful set of substantive themes of relevance to the bloggers' understanding of the relationship between sociability and Internet use.

Finally, in stage 5 (theoretical coding), focused codes were refined into broad thematic categories by looking at how they relate to each other to form a coherent theme. This process resulted in the identification of a set of themes concerning how the bloggers understand the role of geographical location in digital sociability.

Table 1 presents the scale of the Island Blogging project and the size of the sample selected for the thematic analysis. 


\section{Mapping Digital Sociability}

Figures 2-4 show the results of the process of mapping the comments made during the project to uncover patterns in the bloggers' online interactions, at the level of the island groups, the islands, and the individual bloggers and commenters, respectively. In Figures 2 and 3, each circle represents the location of a blogger or commenter. The size of the circles reflects the relative number of contributors (bloggers plus commenters) in each location. The arrows show the direction of the comments flowing from one location to another. The width and opacity of the arrows shows the volume of comments flowing from one location to another (their 'edge weights'). The grey circles next to the coloured circles show 'self-loops' or comments by individuals in one location to individuals in the same location: the thicker the circle, the greater the number of self-loops. Self-loops also indicate when bloggers comment on their own posts, as they often do when replying to comments from others.

In Figures 2-4, the circles are placed according to the Fruchterman-Reingold (1991) algorithm. Fruchterman and Reingold compare their system to that of a planetary simulation (p. 1131), in which each circle is treated as a physical object whose position is influenced by the attractive and repulsive forces around it, albeit this is modelled within the frame of a two-dimensional space. For the purposes of the present analysis, this means that locations connected by large edge weights (volumes of comments) are positioned close to each other because they have a strong attractive force, and less heavily connected locations have a more peripheral placement in the graphs. This effectively reconfigures the spatiality of the islands in relation to each other and to other contributing locations, representing a new digital geography of the islands, as defined by the Island Blogging network.

\section{Connections Across Space}

Figure 2 gives an impression of the whole network by island group. Edge weights (arrows) with a value of less than 63 have been filtered out of this graph to make the strong relationships show more clearly (63 is the average edge weight in the network). The graph shows that comments came from all over the world (marked in purple) with most external commenters coming from mainland Scotland and the rest of the UK, reflecting the UK focus and reach of the $\mathrm{BBC}$ website. Island Blogging Headquarters, marked in red, denotes the BBC moderators. Comments from Scotland and the UK were evenly distributed across the three island groups. Many commenters were based in North America and contributed a large number of comments (more than either mainland Scotland or the rest of the UK), the majority of which were directed towards the Northern and Western Isles. A smaller number of commenters came from Mainland Europe, but the width of the arrows shows that they were active contributors, again with a large volume of comments on blogs from the Western and Northern Isles and fewer on the Argyll and Clyde blogs. Within the

Table 1 Number of blogs, posts, comments and islands in the Island Blogging project and in the sample selected for the thematic analysis

\begin{tabular}{lcccc}
\hline & no. blogs & no. posts & no. comments & no. islands \\
\hline Total & 345 & 5672 & 54,473 & 54 \\
Sample & 161 & 752 & 9836 & 40 \\
\hline
\end{tabular}




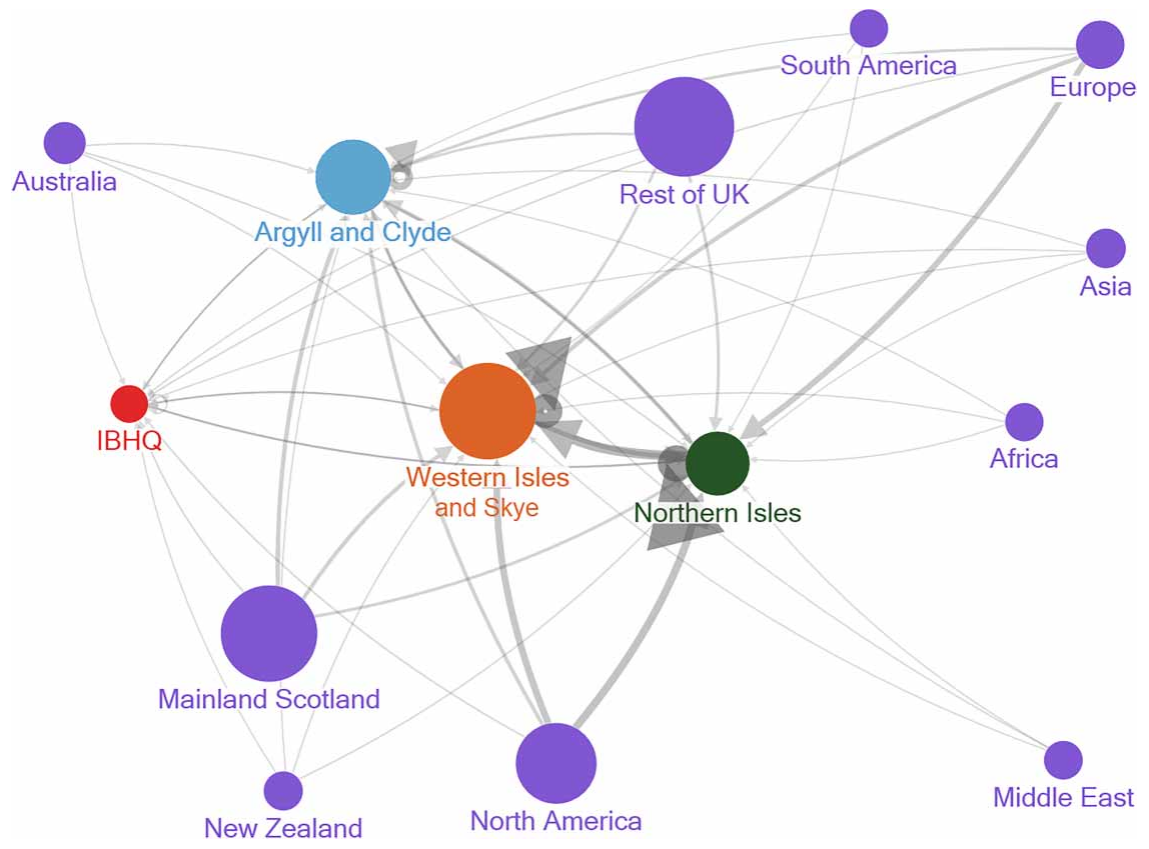

Figure 2 The complete Island Blogging network by island group.

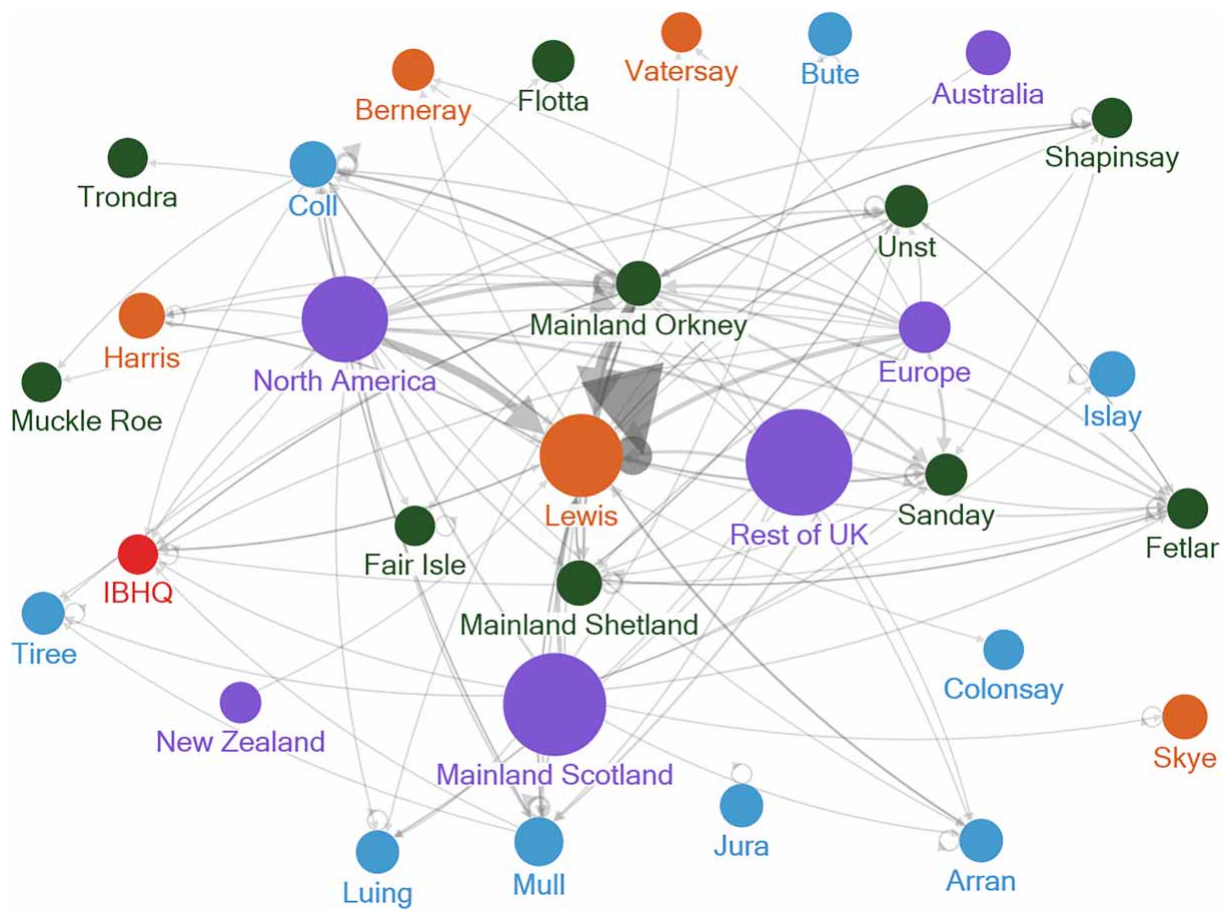

Figure 3 The complete Island Blogging network by island. 


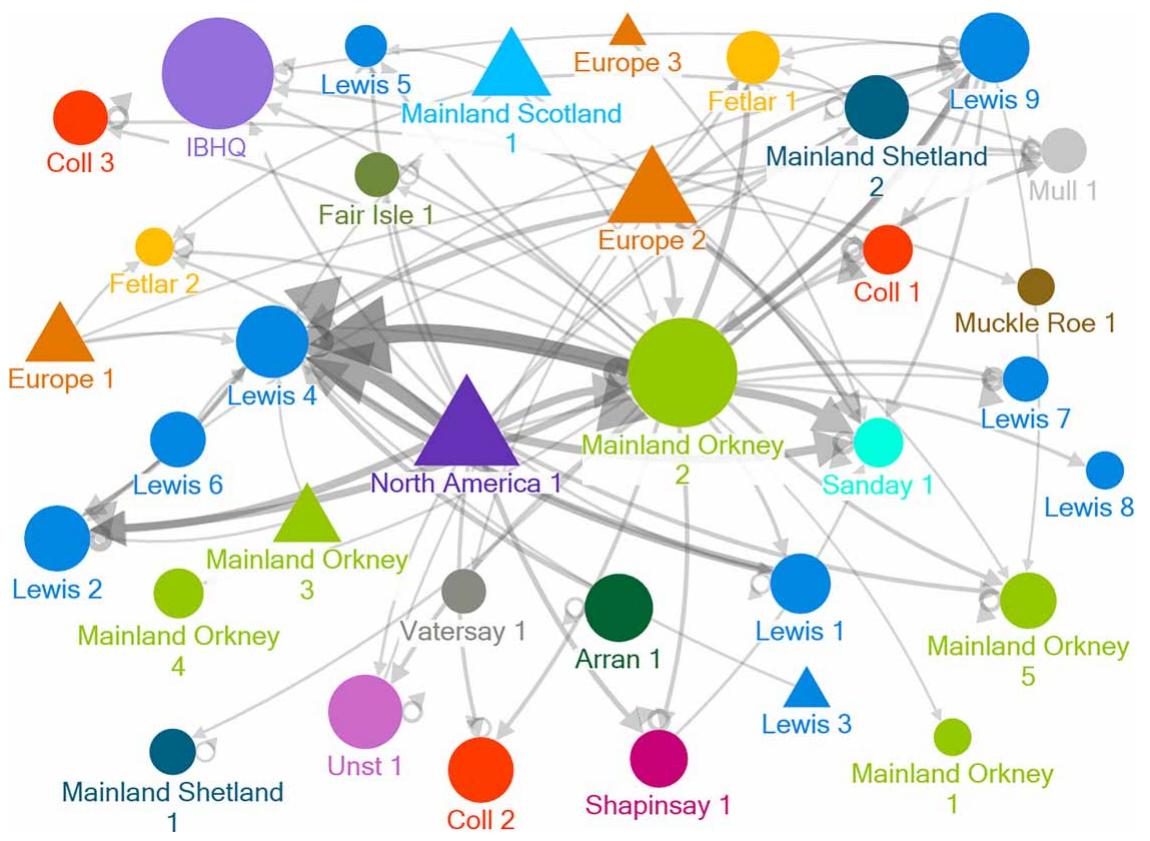

Figure 4 The complete Island Blogging network by individual blogger and commenter. $\bigcirc=$ blogger; $\triangle$ = commenter.

islands, the largest number of commenters on the island blogs came from the Western Isles, followed by Argyll and Clyde and the Northern Isles. The heavy arrow between the Northern Isles and the Western Isles highlights a large amount of interaction between these island groups, and the large self-loops (grey circles) in the same groups indicate high levels of internal discussion.

The Western and Northern Isles are closely linked in this online network, and their international connections (specifically with North America and Europe) appear stronger than their connections with the rest of the country. Argyll and Clyde makes and attracts contributions and also shows a degree of internal commenting but relative to the other island groups it is less active and its role in the overall network is less central.

Figure 3 shows the network in finer detail by mapping activity at the level of the individual islands. Island group is indicated by the colour of the circles: green for the Northern Isles, blue for the Argyll and Clyde islands and orange for the Western Isles and Skye. Red denotes IBHQ and purple circles are for external commenters from outside the Scottish islands. The islands where there was relatively little activity have been filtered out to remove clutter and highlight the significant locations in the network and their relationships.

The fact that most of the circles are of a similar size reflects the fact that they had similar numbers of Island Blogging contributors. Lewis is the exception, with 51 blogs and over 600 commenters, but it has the largest population of the islands $(21,031$ at the time of the 2011 Census); it is also possible that a smaller number of individuals in Lewis commented under a variety of different names. Only four other islands in the Western Isles and Skye grouping remained visible in the network after less active islands were filtered out, highlighting that Lewis is a central actor in this island grouping. Additionally, the grey circle 
attached to Lewis reveals a high degree of internal activity on the Lewis blogs, indicating that contributors from Lewis were commenting on blogs from their own island, possibly on conversations emerging from their own blogs. Lewis appears to be a hub of interaction in the Island Blogging network, both contributing to and attracting conversations with other islands, mainland Britain and internationally. Activity in Argyll and Clyde and the Northern Isles is more evenly distributed between 9 and 10 islands, respectively, with Mainland Orkney also showing a high degree of internal commenting. Mainland Scotland, the rest of the UK and North America have more contributors, reflecting their much larger populations. Of particular note is a triangle of activity between Lewis, Mainland Orkney and North America, with a large volume of comments flowing towards Lewis. This equates to 9723 comments from Mainland Orkney, 9363 from Lewis and 7647 from North America.

The complete Island Blogging network comprised 345 bloggers and 6026 individual commenters. The most active of these are shown in Figure 4 in which they are referred to by pseudonyms that identify them by the location from which they are blogging or commenting (Lewis 1, Coll 2, etc.). Edge weights of less than 80 have been filtered out from the visualisation to allow the prominent relationships to stand out (80 is an arbitrary figure but gives an uncluttered view of the main players in the network); this results in a graph showing the 35 most active contributors. Here, the circles represent bloggers and the triangles represent commenters. In this case, the size of the shapes reflects their out-degree centrality - in other words, the number of comments made by a particular person.

Figure 4 shows that particular individuals are at the heart of the triangle of activity found in Figure 3: blogger Mainland Orkney 2 with 7747 comments, blogger Lewis 4 with 1943 comments and commenter North America 1 with 5888 comments. Other external commenters also play a prominent role, in particular Europe 1, Europe 2 and Mainland Scotland 1.

Each of the island groups has an island with a concentration of active participants. A total of eight bloggers and one commenter are at the heart of Lewis's strong presence in the network analysis, with Vatersay the only other prominent island in the Western Isles. Three bloggers from Coll are active in the Argyll and Clyde grouping, with Arran and Mull also making an appearance. Similarly, five individuals from Mainland Orkney are especially active, the other main Orkney contributor being from Shapinsay. Contributions from Shetland are more dispersed and include bloggers from the Mainland, Fetlar, Unst, Muckle Roe and Fair Isle. Island Blogging Headquarters, the moderator of the blogs, plays an active role throughout the project, the size of its circle showing that it contributed a large number of comments to the blogs. The arrows show that it also received comments from the islands and further afield.

Overall, Figure 4 shows that the Island Blogging community had at its core several key contributors who were highly active, but there were a number of other contributors who were active at a more moderate level and many more who blogged or commented occasionally.

\section{Connections Across Time}

Graphs similar to Figure 3 were also produced for each year of the project, depicting snapshots of the changing span and intensity of the connections between the islands and other locations. Over time, the network can be seen to expand, first in the number of contributors as all of the island groups became eligible to join, and second in the volume of interactions 
between bloggers and commenters, reaching a peak of activity in 2006, 2007 and 2008. Some disruption followed the inclusion of the Western and Northern Isles in 2005, with the initially prominent islands of Mull, Coll and Tiree eclipsed by the new islands of Lewis and Mainland Orkney in terms of the volume of comments attracted by these islands' blogs. However, after this period, patterns of connectivity were established between locations, which grew in intensity over the years. These contributions comprised a core of Lewis, Mainland Orkney and North America, and an otherwise even spread of contributions from across a relatively stable set of contributing locations, many of which are represented as satellites of the core network, occupying more peripheral positions in the graphs, with connections to the centre as well as to other islands and locations. Smaller pockets of activity are visible throughout the height of the project in other islands, particularly in the Northern and Argyll and Clyde island groups. In 2009, the number of active contributors and the volume of comments contracted visibly as the project wound down.

\section{Discussion}

The digital geography created by the bloggers and commenters produces new spatialities of the island groups. This is particularly visible in the case of Lewis and Mainland Orkney, separated by 100 miles of ocean and requiring two flights or ferry journeys to travel between the two, but close neighbours in this digital network. In Figure 3, Lewis is closer to Mainland Orkney than to Harris, to which it is physically joined. Other islands have a more peripheral position in the network and have links with one another that span their physical 'real world' situations and groupings.

The wider world is also reconfigured in relation to the islands in this digital network, with stronger connections to North America than to Mainland Scotland and the rest of the UK, although these remain closely linked. The concentration of activity that emerged over the course of the project between Lewis in the Western Isles, Mainland Orkney in the Northern Isles and North America lends support to assumptions that people living on remote rural islands will use their digital connectivity to overcome their physical isolation and connect with others across space. In the visualisations, these distant locations, separated by 3000 miles of Atlantic Ocean, are brought into proximity digitally. Continental Europe, too, has strong ties with the Western and Northern Isles in the graph showing the network by island group (Figure 2). North America and parts of Europe have longestablished links with the islands, respectively genealogical and historical, which might account for these digital connections.

While attention to the spatial dimensions reveals that the islanders were indeed using the blogs to forge connections that stretched across mainland Britain and beyond, an analysis of the network over time showed that patterns of connectivity between locations are repeated year-on-year. This suggests the formation of a stable, close-knit network of strong ties that developed and deepened over the duration of the project. The network is enduring, lasting as long as the BBC's supporting infrastructure was in place.

\section{Perceptions of Digital Sociability}

The social network analysis shows that the practice of commenting was widespread and the resulting web of interconnections was dispersed, creating a new 'virtual geography' of the 
islands. However, it does not explain how or why these relations emerged or the content of the interactions. These more substantive, qualitative elements are addressed by the thematic analysis, presented in this section, which aims to reach a deeper understanding of how the bloggers perceived spatial dimensions of the sociability enabled by the blogs.

\section{Islands and Connectivity}

Despite the heterogeneity of the islands, they all have in common their separation from one another and from the mainland by water. How the islanders experience geographical connectivity beyond their own islands is therefore associated with the availability of transport links, whether bridge, causeway, ferry or plane, to cross the seas that surround the islands: 'One of the most overwhelming factors of living on an island is our near-total dependence on the ferry service for travelling to and from the mainland' (Mull 4, 21 March 2004).

Throughout the blogs, the cost of using transport links is a recurring theme, a rise in the price of flights or ferry tickets, for example, affecting the islands' accessibility:

Now and again you need to get off the rock but man is it expensive to do it. You got the cost of your ticket and then the cost for cold food on the ferry is just crazy. Isn't it about time they built a tunnel so us islanders don't all go crazy being stuck on this glorious rock????

(Harris 1, 10 October 2007)

Additionally, these connections are dependent on the weather, with all forms of transport to and from the islands subject to favourable conditions. Services are often cancelled and bridges closed in the event of high winds, high and low tides, low visibility, snow or stormy seas:

Suddenly Orkney will become an island again. The strong winds and snow will undoubtedly delay the ferry sailings and possibly even the flights. A strange feeling of being alone, making sure we have prepared because if the snow is really bad, the farm itself will become an island of its own.

(Mainland Orkney 1, 29 January 2008)

The geographical remoteness of the islands, as experienced by islanders, is therefore not fixed, but rather is subject to change according to the weather and fluctuations in transport prices.

The islands' peripherality relative to mainland centres of population, in combination with their reliance on unreliable, sometimes unavailable links, is often reported in the blogs as limiting the islanders' off-island sociability:

We still have a lot of family on the mainland, mostly in the South, and we are constantly saying 'come and see us'. For some, the journey appears too much.

(Lewis 15, 5 April 2007)

The physical boundedness of the islands is explicitly contrasted by the bloggers with the digital connectedness enabled through the blogs. In reflections that echo the hopes of rural policy-makers for digital connectivity (The Royal Society for Edinburgh 2010; 
Defra 2012; Welsh Government 2013), some of the Scottish islanders in the case study are motivated to use the blogs by a desire to overcome the constraints of their geographical location. Through the blogs, they are able to come into contact with people from other areas and countries and expand their social circles:

It gives us the means to travel without even leaving our homes. Even though I live in an isolated area, I am also part of the outside world thanks to my PC. For some folk, that's no big deal. But for me, not having much money, or a car, I find that my travel options are very limited, so I appreciate it even more.

(Mull 2, 22 March 2004)

\section{Local and Global Dimensions}

Indeed, as revealed by the social network analysis, the bloggers make full use of the digital connectivity brought by Island Blogging by interacting with commenters from other countries, reflecting the strong international links depicted in the social network analysis: 'IB has promoted not only communication about the Islands but also between people within the disparate archipelagos and the wider world' (Mainland Orkney 3, 25 November 2008). International contributors to the network are regarded with familiarity and fondness; however, while these connections are highly valued, the bloggers feel that Island Blogging is an inter-island network at its core:

The unique thing about IB is that the blogs are connected by the theme of 'Scottish Islands'. So as well as a set of blogs, it is also a common interest group [...] I can flit from isle to isle like some sort of cyber pub crawler, and flit easily.

(Mull 1, 25 November 2008)

The commonalities of island life, not least their peripherality and physical boundedness, provide points of mutual understanding for the bloggers and bind them together as islanders.

The bloggers' emphasis on the importance of their inter-island connections came to the fore when, in November 2008, the BBC announced that the site would be closing. The posts and comments reacting to the announcement highlight the value placed by the bloggers in being able to connect, through Island Blogging, with residents of other islands and island groups in ways not previously possible. A blogger from Mainland Shetland expresses her fear that the new, virtual geographies enabled by the blogs, which brought the islanders closer together, will dissipate once the infrastructure is gone: 'it's back to the bad old days when the Northern Isles were in their own wee box, the Western Isles were in theirs and so on ...' (Mainland Shetland 3, 25 November 2008).

In this respect, the structure and aims of the Island Blogging initiative are in tune with these islanders' desire to reach beyond the geographical limitations of their physical place yet maintain their unique island identity, which they are able to achieve by connecting with other islanders. They do not seek to escape their island location through their digital connectivity but rather to extend their island network by connecting with each other across the ocean, joining up the spaces between them. 


\section{Boundary Construction: Island Versus Mainland}

After the BBC announced the impending closure of Island Blogging, the bloggers joined together to open a new, independent site. A central theme of their discussions about how to construct the site was a concern to preserve Island Blogging as a Scottish island network. This had both material and virtual dimensions.

Materially, the bloggers often talk about island life in opposition to 'the mainland' (mainland Britain), 'the South' or 'da Sooth', which is conceived as synonymous with the 'rat race', noise, crowds, stress and crime. Being separated from the mainland by water brings a unique set of concerns regarding transport, weather and access to services that, some argue, promotes a distinct island identity. This in spite of the islands' diversity, suggested by 2001 Census data (Fleming 2003) and outlined by Cohen (1987) during his time as an anthropologist on the island of Whalsay in Shetland:

The many islands of the Hebridean groups are themselves starkly different from each other in social complexion. As Gaels, their populations are also ethnically and linguistically distinct from those of the Northern Isles - Orkney and Shetland which have hardly any Gaelic influence. Moreover, although the social connections between Orkney and Shetland have been strengthened through years of intermarriage, and notwithstanding the regular reciprocal visits made by representative groups from each, the two island groups share few interests.

(Cohen 1987, p. 90)

While the bloggers recognise the many demographic, economic and cultural differences between and within the islands, the island/mainland distinction provides common ground and unites them online. That the islanders, across the island groups, are unified by their common differences from mainlanders is summarised by Mainland Orkney 1:

Everyone who lives in these truly unique places suddenly had their own voice which could not be shouted over by those in the mainland. The voices of people who never notice when they order something from a catalogue or the internet that delivery is free for UK mainland only. People who have to lock their doors at night. People who have no idea who their neighbours are. People who cannot comprehend that if the weather is bad, you are stuck. People who think a community is something which lives in a community centre and who's children think that milk and meat comes from the supermarket, eggs have nothing to do with a chicken and mud is a bad thing.

(Mainland Orkney 1, 25 November 2008)

This remit of Island Blogging, that it is for islanders only, is felt to be an important element to carry over to the new site. Even commenters from outwith the islands agree that it should keep the same focus, despite the fact that their interactions with the bloggers would still be restricted to commenting:

I strongly agree with the idea that IB is an ISLAND community and I think it should stay that way [...] Keep IB for the Islanders and let us others have our say in the Comments. 
Virtually, the bloggers are concerned to maintain a balance between local and global connections in the 'big wide blogging world'. They voice their concern that the community they have built will be diluted or even lost when they move to the new site. They feel that the blogs are a distinctively island creation and that they should retain their separation from generic mainland concerns:

I could take my urge to write away to another site, and lost in the anonymity of the big world could probably write loads of stuff I wouldn't dare put on IB, and it might be very funny, in a cruel sort of way, but it would lack the friendliness, the 'don't lock the car' feeling of IB, which is the island way.

(Coll 2, 4 December 2008)

The structure and support provided by the BBC as moderators is felt by the bloggers to be integral to the maintenance of the boundaries that protect them. While the presence of Island Blogging Headquarters (the moderators' online identity) is necessarily conspicuous, with posts and comments being surveyed prior to publication, it is not generally perceived as a negative force. Rather, it is largely regarded as benevolent and approachable, keeping the bloggers 'safe' by enforcing the house rules:

It's moderated, which sometimes can be a little frustrating, but at the end of the day, there's no bad language, no nastiness and, okay occasionally we have a bit of Carry On Style cheeky banter, but nothing too racey.

(Coll 3, 25 November 2005)

For the bloggers, Island Blogging represents a safe, secure place in a digital world that is otherwise an unknown territory:

Please do not leave us out in the cold scarey world of 'real blogging'. We like it cosy by the hearth with a song and a wee dram.

(Westray 1, 25 November 2008)

\section{Discussion}

Many of the bloggers compare the limited connectedness of their offline setting with the unlimited potential of the online world. Indeed, making social contact beyond the edges of their islands fuels many of them to use the blogs as a social tool. Yet, while they enjoy the possibility to overcome their geographical limitations and connect with people worldwide, evidence from the thematic analysis highlights that the bloggers perceive the inter-island nature of the network, and the opportunities it affords to explore their commonalities as islanders, to be a key unifying theme. The tangled mesh of connections revealed by the social network analysis belies a much more simple social structure, as described in the island bloggers' discussions, with islanders at the core and other contributors as secondary members of the network.

The bloggers feel that other Scottish islanders, even those from different island groups hundreds of miles away, have a shared understanding of island life, which they seek to preserve by constructing a collective boundary around themselves in the digital world. For these blogging islanders, location plays a role in the formation of connections online, in 
the sense that it provides a way of navigating new digital territories. As was highlighted by the social network analysis, selected, more distant contacts are a part of this world, but attention to the content of the blogs reveals that the Island Blogging network is an island network at its core.

\section{Concluding Remarks}

Communications technologies present new opportunities for social interactions in island settings, offering the potential to overcome some constraints of island life. In the case of Island Blogging, the global connections afforded by the technology offer the possibility to extend the social circles of the bloggers beyond the physical confines of their islands, enabling them to connect with people throughout the world.

This paper employed a social network analysis and a thematic analysis of the content of the blogs to investigate the role of geographical location in digital sociability for the blogging islanders in the case study. It revealed a highly interactive environment in terms of the number of contributors to the blogs and the volume of interactions they engaged in over the course of the project. The network includes both those who blog on the site (Scottish islanders) and those who only comment (islanders and non-islanders).

In terms of the research question, which addresses the role of geographical location in digital sociability, the social network analysis revealed that the network formed by the islanders was spatially dispersed, showing a 'reconfiguration of places'. Echoing Gillis's (2004) view of 'Atlantic civilisation not as an appendage of European civilization but as something with its own history and geography, as much offshore as onshore' (p. 87), the bloggers' interactions span the island groups and connections are formed through the Island Blogging site with mainland Scotland, the rest of the UK, mainland Europe, North America and further afield, redrawing local and world maps for the digital environment. Islanders are forming new relationships with each other across large distances and spanning oceans, effectively bridging their dispersed geographies, and the world map is rearranged, bringing North America closer to the Northern and Western Isles. Observations of the network over time showed that these new geographies are stable and enduring.

The thematic analysis revealed that the geographical 'apartness' of the islands is a common topic of discussion in the blogs. This the islanders contrast with the geographically unrestricted links enabled by their digital connectivity. Nevertheless, much of their digital communication is concerned with exploring themes of physical isolation and constructing boundaries around their online community. Their understanding of the local and global aspects of their new social context is framed by the common elements that bind them together as Scottish islanders, and they endeavour to preserve their 'islandness' in the global virtual space just as they are geographically distinct in the physical world. In illustration of this, concepts of community, warmth and close-knit friendships, used to describe Island Blogging, are repeatedly contrasted with the scale and strangeness of a mainland other and an uncharted wider Internet:

It is figuratively as if people stand at the boundary and witness its blurring, its fading, feel themselves being tugged across the line. So they reach into their symbolic and cultural reserves to reformulate their sense of distinctiveness from those on the other side.

(Cohen 1987, p. 96) 
Notwithstanding that the connections formed by the islanders occurred across a geographically distributed space, these are hardly the fluid, weak ties envisaged in theories of the network society that emphasise insubstantial connections across ephemeral networks (Castells 2000; van Dijk 2012; Rainie \& Wellman 2012). Rather, as has been discovered in rural studies conducted in other countries (Gilbert et al. 2010; Stern \& Adams 2010), the islanders' location influences how they approach and experience the digital context of the blogs: in this case, their island setting both provides a motivation for blogging and shapes how they use the blogs to form new connections. Place therefore has a strong role in the negotiation of online space and the formation of online ties and identity.

In this respect, the islanders' digital sociability, as expressed through Island Blogging, was revealed to be of a different nature to that envisaged by policy-makers. Rather than using their connectivity to 'overcome' their remoteness and maintain contact with distant friends and family, they formed new relationships with other islanders centring on shared experiences of islandness. Moreover, far from the one-directional impact anticipated in policy discourse (Talbot \& Gillespie 2008, p. 156), their use of the technology was shown to be complex and nuanced.

While there are certainly gains to be made through the use of digital technologies by island residents, it is vital that future assumptions are informed by empirically based studies in island settings. The technology itself offers new possibilities in this regard, offering the potential to gain insight into 'the science of island space' (Moles 1982, p. 481) or, as McCall (1994, p. 7) prefers, 'the study of islands on their own terms', and their changing nature in the digital world.

\section{Funding}

This work was supported by the award made by the RCUK Digital Economy programme to the dot.rural Digital Economy Hub [award reference EP/G066051/1].

\section{References}

BBC Scotland (2010) 'Island blogging' [Online], Available at: http://www.bbc.co.uk/scotland/islandblogging/ (accessed 9 March 2014).

Cairncross, F. (1997) The Death of Distance: How the Communications Revolution Will Change Our Lives (London: Orion Business).

Castells, M. (2000) The Rise of the Network Society, 2nd edn (Cambridge: Wiley-Blackwell).

Castells, M. (2001a) Informationalism and the network society, in: P. Himanen (ed.) The Hacker Ethic and the Spirit of the Information Age, pp. 155-178 (New York: Random House).

Castells, M. (2001b) The Internet Galaxy: Reflections on the Internet, Business and Society (New York: Oxford University Press).

Castells, M. (2005) The network society: from knowledge to policy, in: M. Castells \& G. Cardoso (eds) The Network Society: From Knowledge to Policy, pp. 3-22 (Washington, DC: Center for Transatlantic Relations).

Charmaz, K. (2006) Constructing Grounded Theory: A Practical Guide Through Qualitative Analysis (London: Sage).

Cohen, A. (1987) Whalsay: Symbol, Segment and Boundary in a Shetland Island Community (Manchester: Manchester University Press).

Defra (2012) Statistical Digest of Rural England 2012 (PB13820) (London: Department for Environment, Food and Rural Affairs).

van Dijk, J. (2012) The Network Society (London: Sage).

Durkheim, E. ([1893] 1997) The Division of Labor in Society, W. D. Halls (trans.) (New York: Free Press). 


\section{R. Wilson et al.}

Fleming, A. D. (2003) Scotland's Census 2001: Statistics for Inhabited Islands [Online]. General Register Office for Scotland Occasional Paper No. 10. Available at: http://www.gro-scotland.gov.uk/files1/stats/occasionalpaper-10-inhabited-islands.pdf (accessed 9 March 2014).

Fruchterman, T. M. J. \& Reingold, E. M. (1991) Graph drawing by force-directed placement, Software: Practice \& Experience, vol. 21, no. 11, pp. 1129-1164.

Gannon, R. (2007) Exploring the 'Spatial' Dimension of an 'Information Society': An Investigation of the 'Friction of Distance' in a Rural Irish Community, $\mathrm{PhD}$ thesis, University College Dublin.

Gilbert, E., Karahalios, K. \& Sandvig, C. (2010) The network in the garden: designing social media for rural life, American Behavioral Scientist, vol. 53, no. 9, pp. 1367-1388.

Gillis, J. (2004) Islands of the Mind: How the Human Imagination Created the Atlantic World (New York: Palgrave Macmillan).

Haswell-Smith, H. (2004) The Scottish Islands: A Comprehensive Guide to Every Scottish Island (Edinburgh: Canongate).

Lægran, A. S. (2002) The petrol station and the internet café: rural technospaces for youth, Journal of Rural Studies, vol. 18, no. 2, pp. 157-168.

Malina, A. \& Macintosh, A. (2004) Bridging the Digital Divide: Developments in Scotland (London: Idea Group).

McCall, G. (1994) Nissology: a proposal for consideration, Journal of the Pacific Society, vol. 17, nos. 2-3, pp. 1-8.

Moles, A. (1982) Nissonologie ou science des îles, L'Espace Géographique, vol. 11, no. 4, pp. 281-289.

Pahl, R. (1968) The rural-urban continuum, in: R. Pahl (ed.) Readings in Urban Sociology, pp. 263-305 (Oxford: Pergamon).

Rainie, L. \& Wellman, B. (2012) Networked: The New Social Operating System (Cambridge: MIT Press).

Scottish Executive (2002) Winners in Digital Communities Initiative [Online], Available at: http://www.scotland. gov.uk/News/Releases/2002/03/1380 (accessed 12 March 2014).

Social Media Research Foundation (2014) NodeXL [Online], Available at: http://nodexl.codeplex.com/ (accessed 9 March 2014).

Sorokin, P. \& Zimmerman, C. C. (1929) Principles of Rural-Urban Sociology (New York: Henry Holt).

Spencer, L. \& Pahl, R. (2006) Rethinking Friendship: Hidden Solidarities Today (Princeton, NJ: Princeton University Press).

Stern, M. J. \& Adams, A. E. (2010) Do rural residents really use the internet to build social capital? An empirical investigation, American Behavioral Scientist, vol. 53, no. 9, pp. 1389-1422.

Talbot, H. \& Gillespie, A. (2008) Policy and the rural information society, in: G. Rusten \& S. Skerratt (eds) Information and Communication Technologies in Rural Society: Being Rural in a Digital Age, pp. 155-174 (Abingdon, UK: Routledge).

The Royal Society for Edinburgh (2010) Digital Scotland (Edinburgh: The Royal Society for Edinburgh).

Weber, M. ([1904] 1946) Essays in Sociology, translated, edited and with an introduction by H. H. Gerth \& C. Wright Mills (New York: Oxford University Press).

Welsh Government (2013) Next Generation Broadband Wales [Online], Available at: http://wales.gov.uk/topics/ businessandeconomy/broadbandandict/broadband/ngbw/?lang=en (accessed 28 February 2015).

Wirth, L. (1938) Urbanism as a way of life, The American Journal of Sociology, vol. 44, no. 1, pp. 1-24.

Wittel, A. (2001) Toward a network sociality, Theory, Culture \& Society, vol. 18, no. 6, pp. 51-76. 